\title{
Exogenous Adenosine Triphosphate (ATP) Preserves Proximal Tubule Microfilament Structure and Function In Vivo in a Maleic Acid Model of ATP Depletion
}

Paul S. Kellerman, with the technical assistance of Shannon Norenberg and Naomi Gusé

Division of Nephrology, Department of Internal Medicine, University of California, Davis, Medical Center, Sacramento, California 95817

\begin{abstract}
The hallmark of ischemic acute renal failure is a rapid and early decline in proximal tubule ATP. Since we have previously shown that over half of apical microfilament losses occur within the first 5 min of experimental ischemic injury, we postulated that microfilament ( F-actin) structure and cellular location are dependent on cellular ATP levels. To test this hypothesis, we used maleic acid to selectively inhibit renal cortical ATP production in vivo. Maleic acid significantly decreased tissue ATP and apical F-actin in a dose-dependent manner relative to equimolar sodium chloride controls, yet higher doses of maleic acid quantitatively resulted in net actin polymerization, primarily in the cytoplasm. Functionally, maleic acid decreased glomerular filtration rate (GFR) and tubular reabsorption of sodium $\left(T_{\mathrm{Na}_{\mathrm{a}}}\right)$ in a dose-dependent manner relative to sodium chloride controls. Administration of exogenous ATP resulted in significant increases in tissue ATP, net actin depolymerization, and relocation of $\mathrm{F}$-actin from the cytoplasm back to the apical surface coinciding with increases in GFR and $T R_{\mathrm{Na}}$. Thus, ATP depletion induced by maleic acid resulted in significant cytoskeletal and functional alterations that were ameliorated by exogenous ATP. We therefore conclude that the structure and cellular location of F-actin necessary for normal functioning of proximal tubule cells in vivo is dependent on tissue ATP levels. ( $J$. Clin. Invest. 1993. 92:1940-1949.) Key words: maleic acid • microfilaments - adenosine triphosphate - proximal tubule • actin
\end{abstract}

\section{Introduction}

A very early event during in vivo experimental ischemic acute renal failure is a rapid decrease in ATP to $<10-15 \%$ of control values (1-3). Structurally, ischemic injury is characterized by extensive disruption of the apical surface of proximal tubule cells (4-7). Functionally and biochemically, there is loss of

This work was presented in part at both the American Society of Clinical Research meeting in May 1991 in Seattle, WA, and the American Society of Nephrology meeting in Baltimore, MD, in November 1992.

Address reprint requests to Paul Kellerman, M.D., Division of Nephrology, University of California, Davis, Medical Center, $4301 \mathrm{X}$ Street, Sacramento, CA 95817. 1993

Received for publication 4 August 1992 and in revised form 18 May

J. Clin. Invest

(c) The American Society for Clinical Investigation, Inc. $0021-9738 / 93 / 10 / 1940 / 10 \quad \$ 2.00$

Volume 92, October 1993, 1940-1949 unidirectional transport of solute and epithelial polarity as defined by surface membrane characteristics $(8,9)$. Using spectrofluorometry of rhodamine-phalloidin-stained sections of outer cortical proximal tubules, we have recently demonstrated that the majority of apical filamentous (F-) actin loss occurs during the first $5 \mathrm{~min}$ of experimental ischemic injury (10). Since both ATP depletion and apical microfilament disruption are very early events during ischemia, and the binding of ATP to F-actin has been postulated to be necessary for optimal filamentous actin growth, we hypothesize that microfilament structure and cellular location in vivo are dependent on cellular ATP levels. To test this hypothesis, we utilized maleic acid, an inhibitor of the Krebs cycle that is selectively taken up by renal tubule cells, to decrementally decrease renal ATP levels in vivo. To restore tissue ATP levels in the kidney, we infused exogenous ATP- $\mathrm{MgCl}_{2}$ as previously described by Siegel et al. (3). Thus, this model of in vivo ATP depletion and repletion enabled us to observed ATP-dependent alterations in proximal tubule actin structure and renal tubular and glomerular function.

\section{Methods}

Male Sprague-Dawley rats (Harlan Teklad, Madison, WI) weighing 200-300 g were fed standard rat chow. Animals were injected intraperitoneally with 250,400 , and $1000 \mathrm{mg} / \mathrm{kg}$ of disodium maleic acid (Sigma Immunochemicals, St. Louis, MO), or equimolar amounts of sodium chloride. Animals were anesthetized with sodium pentobarbital $(6.25 \mathrm{mg} / 100 \mathrm{~g}$ rat $\mathrm{wt})$, and killed for renal cortical F-actin staining and renal adenine nucleotide assays 30 and 60 min following injection of maleic acid. A second set of rats was infused with $25 \mu \mathrm{mol}$ of ATP$\mathrm{MgCl}_{2}$ during the last $20 \mathrm{~min}$ before death $60 \mathrm{~min}$ after maleic acid for F-actin staining and adenine nucleotide assays. A third set of rats underwent 30-min urine collections bracketed by arterial blood samples for determination of inulin clearance and tubular handling of sodium $60 \mathrm{~min}$ following maleic acid injection without and with ATP- $\mathrm{MgCl}_{2}$ infusions. Last, for quantitative actin determinations, a fourth set of rats was killed $60 \mathrm{~min}$ after injection with maleic acid without and with exogenous ATP- $\mathrm{MgCl}_{2}$.

Rhodamine-phalloidin staining of F-actin. F-actin in outer cortical renal tissue was stained as previously described (10). Outer cortical tissue slices were quickly frozen in liquid nitrogen, embedded in the cryofixative Tissue-Tek OCT (Miles, Inc., Elkhart, IN), and 5- $\mu \mathrm{m} \mathrm{sec-}$ tions cut on a cryotome ( 2800 Frigocut; Reichert Scientific Instruments, Buffalo, NY). Following fixation in $3.7 \%$ formaldehyde, the sections were stained with 1:10 dilution of rhodamine-phalloidin (Molecular Probes, Inc., Eugene, OR). Following mounting in 1:1 PBS/ glycerol, the samples were viewed with a Leitz Orthoplan universal largefield microscope (Orthoplan; E. Leitz, Inc., Rockleigh, NJ) equipped with a ploemopak 2.1 fluorescence vertical illuminator containing an excitation / barrier filter specific for rhodamine. Photographs were taken with a Vario Orthomat 2 microscopic camera and the Ploemopak (E. Leitz, Inc.). The exposure time was variable and automati- 
cally adjusted by the camera unit dependent on the amount of fluorescence quenching.

Spectrofluorometry. The technique of spectrofluorometry is well established $(11,12)$ and has been previously performed with this fluor by us and others $(10,13)$. Apical fluorescence of rhodamine-phalloidin, which is linearly related to F-actin concentration (14), was measured with a MPV compact microscope photometer (E. Leitz, Inc.) mounted on the fluorescence microscope. The microspectrophotometer was interfaced with an IBM personal computer through a customdesigned card and software that allowed the computer to control the shutter sequencers, to average fluorescence in a $250-\mathrm{ms}$ window, and to compile data. Because of the distinct qualitative differences between experimental groups, it was not possible to blind the observer to the experimental protocol. Thus, the following criteria were utilized to standardize the observations: ( $a$ ) All sections were $5 \mu \mathrm{m}$ thick. (b) Saturating quantities of rhodamine-phalloidin were used. There was no difference in quantitative fluorescence found between 1:20 and 1:10 dilutions. (c) The spectrofluorometry field was less than $1 \times 1 \mu \mathrm{m}$ and was placed entirely within the apical fluorescence for each reading. (d) All observations were made within $1 \mathrm{~s}$ of field placement to minimize fluorescence quenching. To minimize reading fluorescence outside the spectrofluorometry field, the microscope field diaphragm was maximally closed. $(e)$ To eliminate interassay variability in fluorescence due to staining, spectrofluorometry field size, or decline in photon emission with increasing lamp time, each experiment included a new control kidney, with all specimens undergoing sectioning, staining, and quantification the same day. $(f)$ For each slide, mean fluorescence expressed in $\mathrm{mV}$ was obtained from 50 observations of tubules, with each observation consisting of a separate tubule. Although mean absolute fluorescence was measured within each experiment, summation data were standardized by expressing the percent change in mean fluorescence relative to the controls within the same experiment. $(g)$ The validity of the technique using independent observations by two individuals has previously demonstrated a correlation coefficient of 0.96 $(P<0.001)(10)$.

DNAase inhibition assay. Actin was quantified as originally described by Blikstad et al. (15) and modified by Cheung et al (16). 60 min after maleic acid injection, the outer cortices were homogenized with a polytron (PT-3000; Brinkmann Instruments, Inc., Westbury, $\mathrm{NY}$ ), and the lysates mixed 1:1 with buffer containing $10 \mathrm{mM}$ Tris$\mathrm{HCl}(\mathrm{pH}=7.5), 150 \mathrm{mM} \mathrm{NaCl}, 3 \mathrm{mM} \mathrm{MgCl}, 0.1 \%$ Triton X-100, 0.2 mM ATP, and $0.1 \mathrm{mM}$ dithioerythritol. Beef pancrease DNAase I (Sigma Immunochemicals) was mixed with $3 \mathrm{ml}$ of calf thymus DNA type I (Sigma Immunochemicals) to obtain a maximal rate of $0.25-0.3$ $\mathrm{OD} \mathrm{U} / 15 \mathrm{~s}$ as measured at $260 \mathrm{~nm}$ at $25^{\circ} \mathrm{C}$. Following construction of a standard inhibition curve using sonicated monomeric actin from rabbit muscle (Sigma Immunochemicals), equal amounts of lysate samples were added to the DNAase, followed 2-4 s later by DNA substrate, with the percent inhibition read at $260 \mathrm{~nm}$. To assay total actin, F-actin was depolymerized by mixing the lysate with an equal volume of a 1.5 $M$ guanidine hydrochloride solution containing $1 \mathrm{mM} \mathrm{CaCl}_{2}, 2 \mathrm{mM}$ Tris- $\mathrm{HCl}(\mathrm{pH}=7.5)$, and $1 \mathrm{mM} \mathrm{ATP}$, and the absorbance was again measured at $260 \mathrm{~nm}$. Protein determination via the Lowry method (17) allowed standardization of actin per $\mathrm{mg}$ of protein between experimental groups. Only DNAase inhibition experiments with standard curves showing $r$ values of $>0.99$ were considered valid, and experimental values falling between $25-75 \%$ inhibition were used in all calculations.

Adenine nucleotide assays. Adenine nucleotides were measured following extraction with perchlorate as per Williamson and Corkey (18). Whole rat kidneys were quickly frozen between stainless steel tongs cooled in liquid nitrogen and pulverized with a liquid nitrogen-cooled stainless steel mortar and pestle in preparation for extraction. After a small amount of the powdered tissue was placed in a drying oven at $105^{\circ} \mathrm{C}$ for $24 \mathrm{~h}$, the remainder was placed in a centrifuge tube on crushed dry ice and extracted with cold $8 \%$ perchlorate $(3.5: 1 \mathrm{wt} / \mathrm{wt})$. Following homogenization at $7500 \mathrm{rpm}$ on a polytron (PT-3000;
Brinkmann Instruments, Inc.) and centrifugation at $12,000 \mathrm{rpm}$ for 10 min, the supernatant was saved. The remaining pellet was again extracted with $6 \%$ perchlorate $(2.5: 1 \mathrm{wt} / \mathrm{wt})$, homogenized, and centrifuged as above. The supernatants were then pooled, $2 \mathrm{~N} \mathrm{KOH} / 0.5 \mathrm{M}$ triethanolamine added to neutralize the $\mathrm{pH}$ to $6-7$, the sample centrifuged at $9,000 \mathrm{rpm}$ for $10 \mathrm{~min}$, and the resultant supernatant saved for adenine nucleotide assays.

Adenine nucleotides were measured enzymatically (19) on a spectrophotometer (UV160U; Shimadzu Scientific Instruments, Inc., Columbia, MD). ATP was measured by mixing Tris base $(0.5 \mathrm{M})$, glucose $(0.2 \mathrm{M})$, NADP $(2 \mathrm{mg} / \mathrm{ml})$, and the extracted supernatant and obtaining a baseline absorbance reading at $340 \mathrm{~nm}$. Hexokinase/ G6PDH $(200 \mathrm{U} / \mathrm{ml})$ was then added, the absorbance read at $60 \mathrm{~min}$, and the concentration of ATP in $\mu \mathrm{mol} / \mathrm{ml}$ calculated by dividing the difference in readings by 6.22 , the coefficient of extinction. ADP and AMP were measured by mixing extracted supernatant with triethanolamine $(50 \mathrm{mM}), \mathrm{MgCl}_{2}(10 \mathrm{mM})$, phosphoenolpyruvate $(10 \mathrm{mg} /$ $\mathrm{ml})$, ATP (6 mM), NADH $(2 \mathrm{mg} / \mathrm{ml})$ and lactate dehydrogenase $(5$ $\mathrm{mg} / \mathrm{ml})$. Following the baseline reading, $10 \mu \mathrm{l}$ of pyruvate kinase $(2.5$ $\mathrm{mg} / \mathrm{ml}$ ) was added, the second reading obtained, and ADP concentration calculated from the difference in the readings divided by the coefficient of extinction. Myokinase ( $5 \mu \mathrm{l}$ of $2 \mathrm{mg} / \mathrm{ml}$ ) was then added, the final reading obtained, and AMP concentration calculated from the difference of the second and third readings divided by two times the coefficient of extinction.

Functional studies. $60 \mathrm{~min}$ following injection of maleic acid, inulin clearances and sodium handling were measured during a $30-\mathrm{min}$ collection period. Following general anesthesia with sodium pentobarbital $(6.25 \mathrm{mg} / 100 \mathrm{~g}$ rat $\mathrm{wt})$, the femoral vein and artery were cannulated with Intramedic polyethylene PE-50 tubing (Clay Adams, Parsippany, $\mathrm{NJ}$ ) and the inulin, dissolved in normal saline, infused at 3.78 $\mathrm{ml} / \mathrm{h}$. The animals were then injected intraperitoneally with either disodium maleic acid or equimolar sodium chloride, and subsequently underwent bladder cannulation and tracheostomy. Following $60 \mathrm{~min}$ of inulin infusion to attain steady plasma levels, urine was collected for $30 \mathrm{~min}$, with arterial blood samples collected at the start and finish of the urine collection.

Inulin was measured using a standard anthrone assay. Briefly, a standard curve from stock inulin and dilutions of plasma (1:10) and urine $(1: 1000$ or $1: 2000)$ were prepared. Following addition of $70 \%$ sulfuric acid and anthrone reagent $(0.2 \mathrm{~g}$ in $100 \mathrm{ml}$ of $70 \%$ sulfuric acid), the samples were incubated at $50^{\circ} \mathrm{C}$ for $30 \mathrm{~min}$, cooled to room temperature, and read at $630 \mathrm{~nm}$.

Plasma and urine sodium values were determined by flame photometry (Beckman Instruments, Fullerton, CA).

Statistics. Data were analyzed for significance using ANOVA, with simultaneous multiple comparisons between groups using Duncan's test. Results were considered statistically different if the $P$ value was at least $<0.05$, and reported as $P<0.05$ or NS. Variance was expressed as standard error of the mean.

\section{RESULTS}

Effect of maleic acid on renal adenine nucleotides, proximal tubule apical F-actin, tubular handling of sodium, and glomerular filtration rate. Maleic acid caused significant dose-dependent decreases in tissue ATP, total adenine nucleotides, and apical F-actin.

As shown in Table I, $250 \mathrm{mg} / \mathrm{kg}, 400 \mathrm{mg} / \mathrm{kg}$, and 1000 $\mathrm{mg} / \mathrm{kg}$ of maleic acid significantly decreased ATP levels in a dose-dependent manner to $82.9 \%, 52.5 \%$, and $37.3 \%$ of control values, respectively. Tissue ADP decreased and tissue AMP increased with maleic acid, but these changes occurred in a non-dose-dependent manner. Primarily because of the decre- 
Table I. Renal Adenine Nucleotides following Maleic Acid without and with Exogenous ATP- $\mathrm{MgCl}_{2}$

\begin{tabular}{lcccc}
\hline \multicolumn{1}{c}{ Treatment } & \multicolumn{1}{c}{ ATP } & ADP & \multicolumn{1}{c}{ AMP } & \multicolumn{1}{c}{ TAN } \\
\hline Control & $1.58 \pm 0.04$ & $0.303 \pm 0.01$ & $0.127 \pm 0.003$ & $2.03 \pm 0.04$ \\
$250 \mathrm{mg} / \mathrm{kg}$ & $1.31 \pm 0.03^{*}$ & $0.286 \pm 0.01$ & $0.129 \pm 0.008$ & $1.79 \pm 0.06^{*}$ \\
$400 \mathrm{mg} / \mathrm{kg}$ & $0.83 \pm 0.09^{*}$ & $0.287 \pm 0.01$ & $0.163 \pm 0.014^{*}$ & $1.28 \pm 0.09^{*}$ \\
$1000 \mathrm{mg} / \mathrm{kg}$ & $0.59 \pm 0.03^{*}$ & $0.264 \pm 0.01^{*}$ & $0.149 \pm 0.004^{*}$ & $1.11 \pm 0.10^{*}$ \\
$400 \mathrm{mg} / \mathrm{kg}$ & & & & \\
$\quad+\mathrm{ATP}$ & $1.12 \pm 0.05^{\ddagger}$ & $0.35 \pm 0.02^{\ddagger}$ & $0.161 \pm 0.01$ & $1.68 \pm 0.02^{\ddagger}$ \\
\hline
\end{tabular}

All values are expressed in $\mu \mathrm{mol} / \mathrm{g}$ wet kidney wt. ${ }^{*} P<0.05$ vs. controls, ${ }^{\ddagger} P<0.05$ vs. $400 \mathrm{mg} / \mathrm{kg}(n=17$ for controls, $n=6$ for 250 and $400 \mathrm{mg} / \mathrm{kg}, n=12$ for $1000 \mathrm{mg} / \mathrm{kg}$, and $n=5$ for $400 \mathrm{mg} / \mathrm{kg}$ plus exogenous ATP).

mental ATP changes, total adenine nucleotides decreased in a dose-dependent manner.

Fig. $1 A$ demonstrates rhodamine-phalloidin staining of control proximal tubules, with smooth homogenous apical fluorescence representing apical brush border and terminal web microfilaments, and little F-actin fluorescence in the cytoplasm. Treatment with $250 \mathrm{mg} / \mathrm{kg}$ of maleic acid (Fig. $1 B$ ) caused significant inhomogeneity and losses (arrows) of the apical fluorescence of F-actin relative to controls, yet there was no change in the scant cytoplasmic F-actin. $400 \mathrm{mg} / \mathrm{kg}$ (Fig. 1 $C$ ) and $1000 \mathrm{mg} / \mathrm{kg}$ (Fig. $1 \mathrm{D}$ ) of maleic acid caused progressive significant losses of apical F-actin fluorescence, with fluorescence appearing in the cytoplasm. Apical fluorescence was quantified using spectrofluorometry (Fig. 2). 250, 400, and $1000 \mathrm{mg} / \mathrm{kg}$ of disodium maleic acid progressively and significantly decreased apical F-actin by $24.1 \pm 1.9 \%, 34.5 \pm 6.5 \%$, and $54.6 \pm 2.2 \%$, respectively, relative to controls. Fig. 3 represents two focal planes of the same tubules $60 \mathrm{~min}$ after treatment with $400 \mathrm{mg} / \mathrm{kg}$ of maleic acid. While higher doses of maleic acid resulted in severe apical F-actin degradation $(A)$, extensive new appearance of F-actin occurred throughout the cytoplasm $(B)$.

The specificity of maleic acid was demonstrated by two different means. When compared with noninjected controls, animals injected with sodium equimolar $(3.13 \mathrm{M})$ to $1000 \mathrm{mg} /$ $\mathrm{kg}$ of disodium maleic acid showed no differences in proximal tubule F-actin staining or renal ATP $(1.61 \pm 0.04$ vs. $1.58 \pm 0.04$ $\mu \mathrm{mol} / \mathrm{g}$ wet wt kidney). Furthermore, the injection of $400 \mathrm{mg} /$ $\mathrm{kg}$ of the maleic acid isomer, sodium fumarate, showed no differences in apical F-actin staining or renal ATP $(1.61 \pm 0.06$ vs. $1.58 \pm 0.04 \mu \mathrm{mol} / \mathrm{g}$ wet wt kidney).

Since maleic acid caused dose-dependent apical structural changes, the effect of maleic acid on renal function was also evaluated. There were significant dose-dependent decreases in glomerular filtration rate (GFR) ${ }^{1}$ as measured by inulin clearances relative to equimolar sodium chloride controls (Fig. 4). 250,400 , and $1000 \mathrm{mg} / \mathrm{kg}$ decreased GFR to $56.2 \%, 34.8 \%$, and $12.4 \%$, respectively, of control values as measured in $\mathrm{ml} /$ min per $g$ kidney $(1.3 \pm 0.13$ vs. $0.73 \pm 0.17,1.41 \pm 0.17$ vs. $0.49 \pm 0.08,1.29 \pm 0.15$ vs. $0.16 \pm 0.03 ; P<0.05$ for all groups vs.

1. Abbreviation used in this paper: GFR, glomerular filtration rate. controls). There were no significant differences in GFR between noninjected controls and control animals injected with increasing equimolar doses of sodium chloride ( $1.52 \pm 0.12$ vs. $1.3 \pm 0.13,1.41 \pm 0.17$, and $1.29 \pm 0.15 \mathrm{ml} / \mathrm{min}$ per $\mathrm{g}$ kidney) Fig. 5 demonstrates alterations in tubular reabsorption of sodium following maleic acid relative to equimolar sodium chloride controls. Although there was a slight downward trend as expected due to the kidneys' normal response to the progressive sodium loads, there were no differences between 250,400 , and $1000 \mathrm{mg} / \mathrm{kg}$ relative to noninjected controls $(99.5 \pm 0.18 \%$ vs. $98.5 \pm 0.17 \%, 97.8 \pm 0.17 \%$, and $96.3 \pm 0.66 \%$, respectively). When compared with equimolar saline controls, $250 \mathrm{mg} / \mathrm{kg}$, $400 \mathrm{mg} / \mathrm{kg}$, and $1000 \mathrm{mg} / \mathrm{kg}$ of maleic acid significantly decreased tubular reabsorption of sodium in a dose-dependent manner ( $92.5 \pm 3 \%, 81.2 \pm 3 \%$, and $33.7 \pm 6.1 \%$, respectively).

Thus, maleic acid induced dose-dependent decreases in tissue ATP and ADP, apical microfilaments, glomerular filtration rate, and proximal tubule reabsorptive function.

Effect of exogenous ATP on renal adenine nucleotides, proximal tubule apical microfilaments, actin polymerization, tubular function, and glomerular filtration rate. To test the specificity of the association of tissue ATP and microfilament structure and cellular location, we infused $25 \mu \mathrm{mol}$ of exogenous ATP- $\mathrm{MgCl}_{2}$ into rats following injection of high-dose maleic acid. Exogenous ATP- $\mathrm{MgCl}_{2}$ increased tissue ATP and reversed the proximal tubule cytoskeletal and functional alterations seen with ATP depletion induced by maleic acid.

$30 \mathrm{~min}$ after injection of $400 \mathrm{mg} / \mathrm{kg}$ of maleic acid, ATP had significantly decreased to $57.9 \%$ of controls ( $1.59 \pm 0.04$ vs. $0.92 \pm 0.06 \mu \mathrm{mol} / \mathrm{g}$ wet wt kidney) (Fig. 6). Without addition of exogenous ATP- $\mathrm{MgCl}_{2}$, at 60 min following injection, ATP was $52.2 \%$ of control values $(1.59 \pm 0.04$ vs. $0.83 \pm 0.09 \mu \mathrm{mol} / \mathrm{g}$ wet wt kidney, $P<0.05$ ). Following infusion of exogenous ATP- $\mathrm{MgCl}_{2}$ during the last $20 \mathrm{~min}$, ATP levels significantly increased to $70.4 \%$ of control values $(1.12 \pm 0.05 \mu \mathrm{mol} / \mathrm{g}$ wet wt kidney) when compared with either 30 or 60 min of maleic acid alone (Fig. 6, Table I). ADP levels also significantly increased, whereas AMP levels remained unchanged (Table I). Fig. 7, $A$ and $B$, are two focal planes of the same tubules demonstrating the alterations in microfilament staining seen $30 \mathrm{~min}$ following injection with $400 \mathrm{mg} / \mathrm{kg}$ of maleic acid and before exogenous ATP- $\mathrm{MgCl}_{2}$ infusion. Fig. $7 \mathrm{~A}$ demonstrates proximal tubule $(p)$ apical F-actin disruption, and Fig. $7 B$ shows F-actin appearing in the cytoplasm of kidneys, identical to that seen in Fig. $360 \mathrm{~min}$ following maleic acid injection. In contrast to the proximal tubules, there was no effect of ATP depletion on the typical basolateral F-actin staining of distal tubules (d). Fig. 7, $C$ and $D$ demonstrate the changes seen in the proximal tubules $60 \mathrm{~min}$ after treatment with $400 \mathrm{mg} / \mathrm{kg}$ of maleic acid followed by exogenous ATP- $\mathrm{MgCl}_{2}$. A low power view (Fig. $7 C$ ) demonstrates that the F-actin has moved from the cytoplasm back to the apical portions of all the proximal tubule cells. The distal tubule $(D)$ F-actin remains unchanged with ATP repletion. A high-power view further details the movement of F-actin out of the cytoplasm and back toward the apical surface (arrow) in proximal tubules. Additionally, a bright yellow line (arrowhead) has appeared at the apex of the cells, likely representing addition of new F-actin to the distal ends of microfilaments in the microvilli. Quantification with spectrofluorometry after $400 \mathrm{mg} / \mathrm{kg}$ of maleic acid plus ATP demonstrated improvement of mean apical fluorescence to lev- 

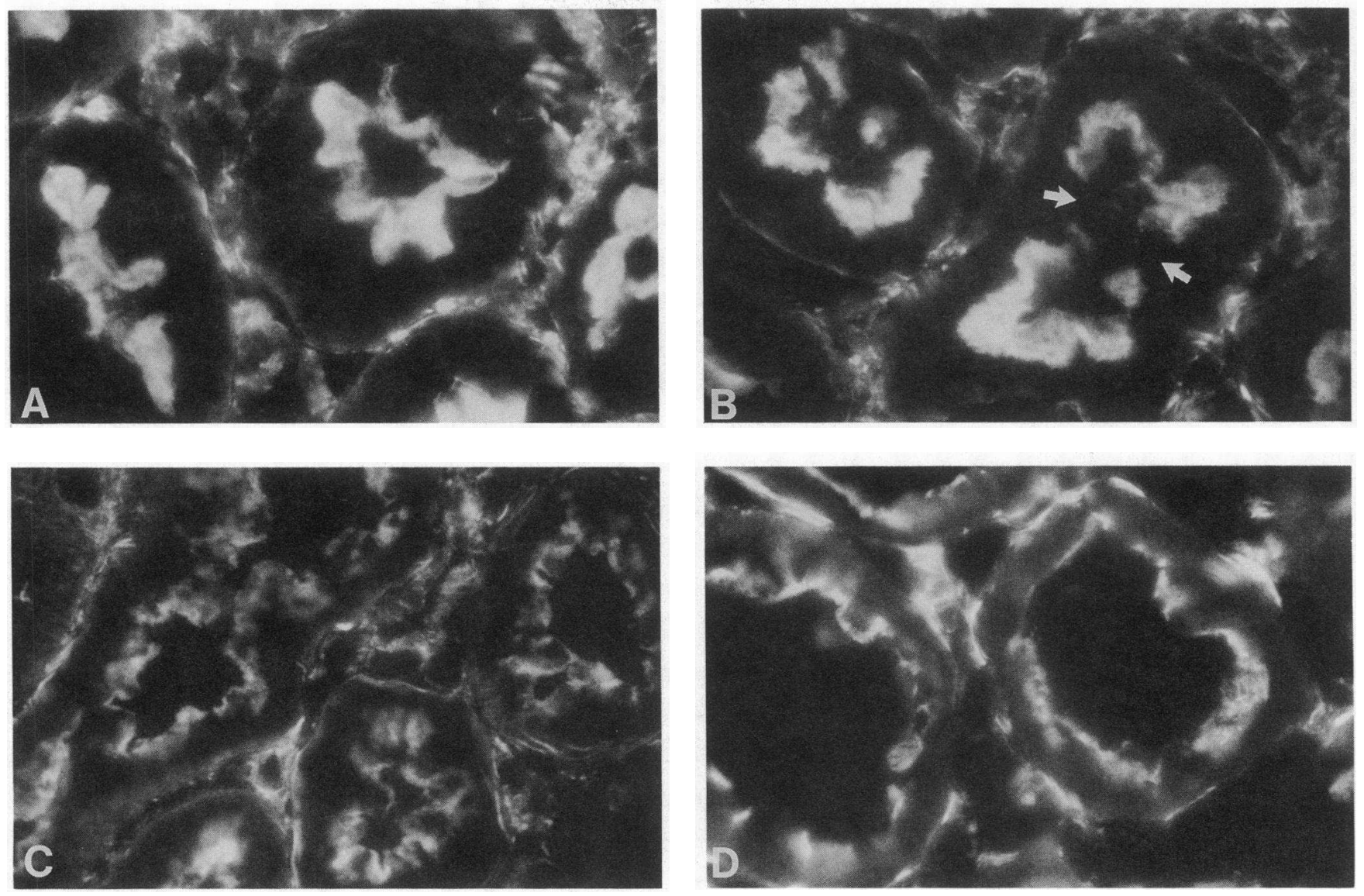

Figure 1. Rhodamine-phalloidin fluorescence of F-actin in proximal tubules treated with maleic acid. Formaldehyde( $3.7 \%)$-fixed sections $(5 \mu \mathrm{m})$ of superficial renal cortex were stained with a 1:10 dilution of rhodamine-phalloidin. $(A)$ Cross-sections of control proximal tubules with homogenous apical fluorescence of F-actin. (B) Following $250 \mathrm{mg} / \mathrm{kg}$ of maleic acid, apical fluorescence decreased and became inhomogeneous with patchy areas of microfilament losses (arrows). (C) Following $400 \mathrm{mg} / \mathrm{kg}$ of maleic acid, there were extensive losses of apical F-actin, with increases in cytoplasmic fluorescence. $(D)$ Following $1000 \mathrm{mg} / \mathrm{kg}$ of maleic acid, there was almost complete loss of apical F-actin, with cytoplasmic opacification by $\mathrm{F}$-actin staining. Magnification was $984 \times$ for $A, B, C$, and $D$.

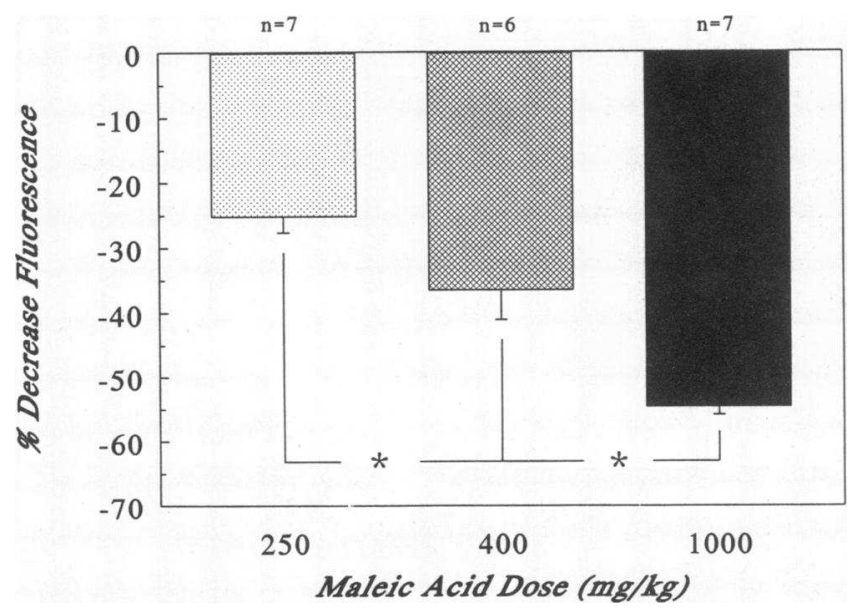

Figure 2. Maleic acid-induced quantitative changes of proximal tubule apical F-actin fluorescence relative to controls. Apical F-actin significantly decreased in a dose-dependent manner following maleic acid. See Methods for detailed description of spectrofluorometry. ${ }^{*} P$ $<0.05$. els seen with $250 \mathrm{mg} / \mathrm{kg}$ of maleic acid, approaching but not reaching statistical significance when compared with $400 \mathrm{mg}$ / $\mathrm{kg}$ of maleic acid alone.

To quantify changes in cellular actin polymerization, G-actin and total actin were measured with the DNAase inhibition assay (Fig. 8). $60 \mathrm{~min}$ following $400 \mathrm{mg} / \mathrm{kg}$ of maleic acid, both percent (top graph) and quantity (bottom graph) of G-actin significantly decreased from $56.7 \pm 1.2 \%$ to $44.7 \pm 1.8 \%$, and $0.345 \pm 0.026$ to $0.264 \pm 0.11 \mathrm{mg} / \mathrm{mg}$ of protein, respectively. Administration of exogenous ATP- $\mathrm{MgCl}_{2}$ following maleic acid significantly increased the percentage of G-actin back toward control levels relative to maleic acid alone $(50.8 \pm 1.1 \%$ vs. $44.7 \pm 1.8 \%$ ), while G-actin quantity increased relative to maleic acid alone, approaching but not reaching statistical significance $(0.318 \pm 0.023$ vs. $0.264 \pm 0.11 \mathrm{mg} / \mathrm{mg}$ of protein $)$. Total actin remained unchanged with ATP depletion and repletion (data not shown). Thus, ATP depletion resulted in net F-actin polymerization, while partial restoration of cellular ATP with exogenous ATP- $\mathrm{MgCl}_{2}$ resulted in net actin depolymerization back toward control values.

Functionally, GFR significantly improved in those animals 

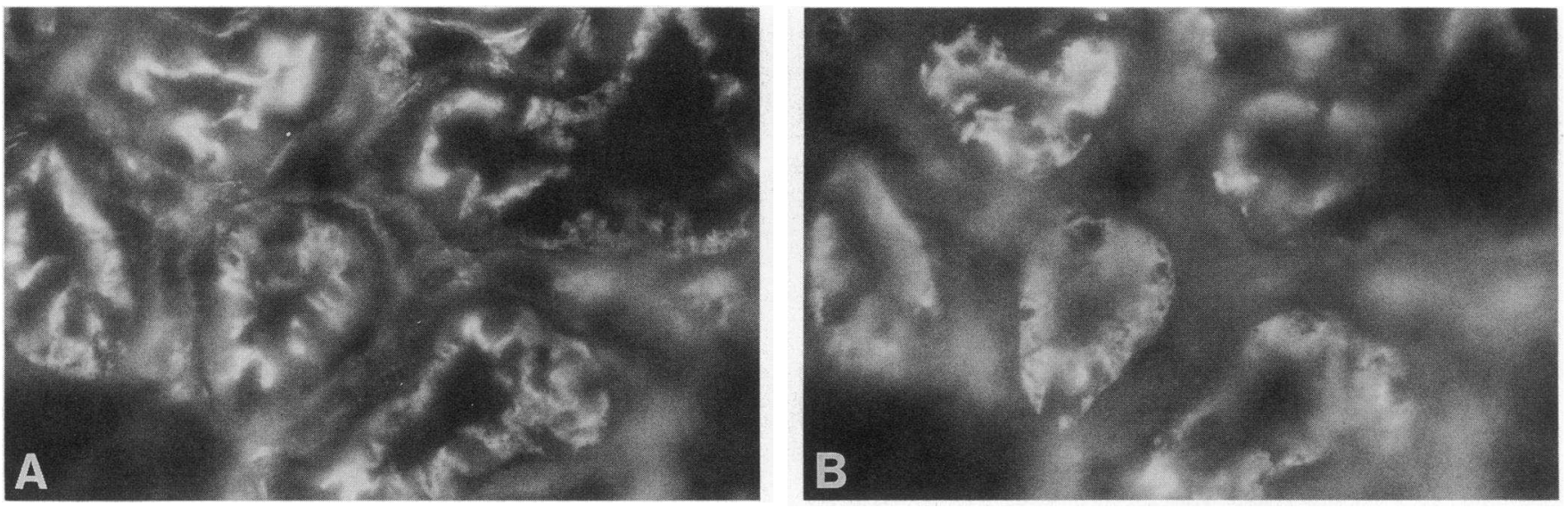

Figure 3. Effect of high dose maleic acid on outer cortical proximal tubules stained with rhodamine-phalloidin. $(A)$ Following $400 \mathrm{mg} / \mathrm{kg}$ of maleic acid, there were extensive apical losses of proximal tubule $\mathrm{F}$-actin. $(B) \mathrm{A}$ different focal plane of the same tubules demonstrating the appearance of F-actin throughout the cytoplasm. Magnification was $\times 787$ for $A$ and $B$.

treated with $400 \mathrm{mg} / \mathrm{kg}$ of maleic acid with exogenous ATP$\mathrm{MgCl}_{2}$ vs. those who received $400 \mathrm{mg} / \mathrm{kg}$ of maleic acid alone $(0.79 \pm 0.08$ vs. $0.49 \pm 0.08 \mathrm{ml} / \mathrm{min}$ per g kidney) (Fig. $9 A)$. Similarly, tubular sodium reabsorption improved significantly with maleic acid followed by exogenous ATP vs. maleic acid alone $(90.1 \pm 2.7 \%$ vs. $81.2 \pm 3 \%$ ) (Fig. $9 B$ ).

\section{Discussion}

In polarized epithelial cells, distinct membrane domains enable functional specialization. Proximal tubule cells unidirectionally transport solute from lumen to blood and have a specialized apical membrane domain both with microvilli for increased resorptive surface area as well as lipid and integral membrane proteins distinct from the basolateral membrane (20).

The actin cytoskeleton is a dynamic organelle in nonmus-

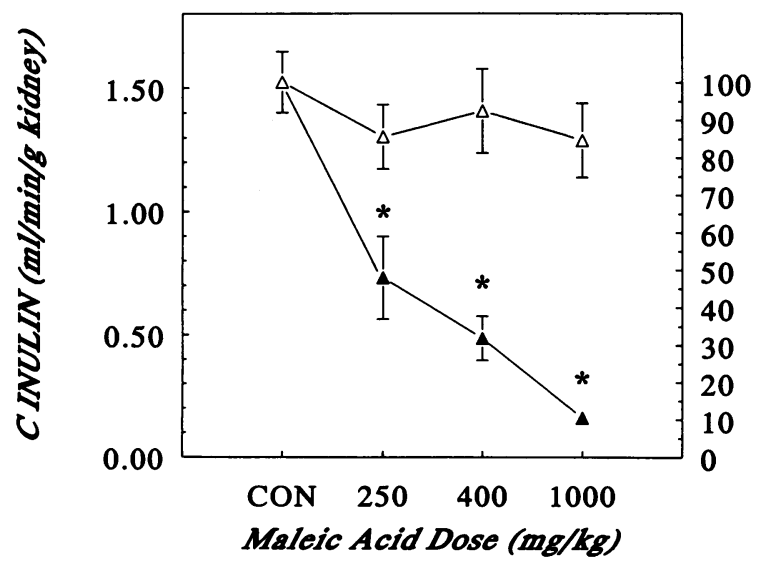

Figure 4. Dose-dependent decreases in glomerular filtration rate (GFR), as measured by inulin clearance, following maleic acid. Inulin clearances were measured by anthrone assay $60 \mathrm{~min}$ following maleic acid injection. Open triangles, noninjected controls $(n=6)$, or animals injected with equimolar $\mathrm{NaCl}(n=10,6$, and 11, respectively); filled triangles, maleic acid-treated animals $(n=6,10$, and 6 , respectively). ${ }^{*} P<0.05$. cle cells such as proximal tubule cells. G-actin, or monomeric actin, is soluble in the cytoplasm and is polymerized to F-actin, or microfilaments $(21,22)$. The major structural component of the microvilli of proximal tubule cells is F-actin, arranged in bundles of 30-50 microfilaments attached via vinculin to the distal tips of the microvilli and attached proximally to a submembranous band of actin known as the terminal web. Linking microfilaments to the surface membrane and to other filaments are multiple actin-associated proteins, some whose actions are calcium dependent. The terminal web in turn attaches to the cell membrane at both the tight and intermediate junctions $(23,24)$.

During experimental ischemic injury to proximal tubules in vivo, ATP decreases to $25 \%$ of control values within $30 \mathrm{~s}$, and below $10-15 \%$ of control values within $5 \min (1-3)$. Decreases in ATP have been shown to cause significant disruption of microfilament bundles in fibroblasts (25), endothelial (26),

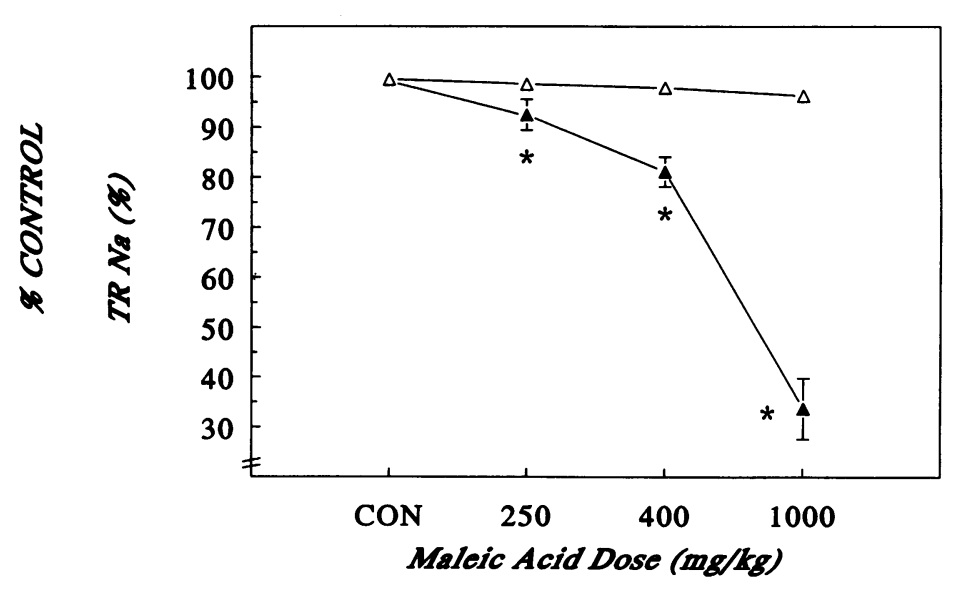

Figure 5. Dose-dependent decreases in tubular reabsorption of sodium $\left(T R_{\mathrm{Na}}\right)$ following maleic acid. $T \mathrm{R}_{\mathrm{Na}}$ was measured 60 min after maleic acid injection. Open triangles, noninjected control animals $(n=5)$ or animals injected with equimolar $\mathrm{NaCl}(n=10,5$, and 11, respectively); filled triangles, maleic acid-treated animals $(n=6,11$, and 5 , respectively). ${ }^{*} P<0.05$. 


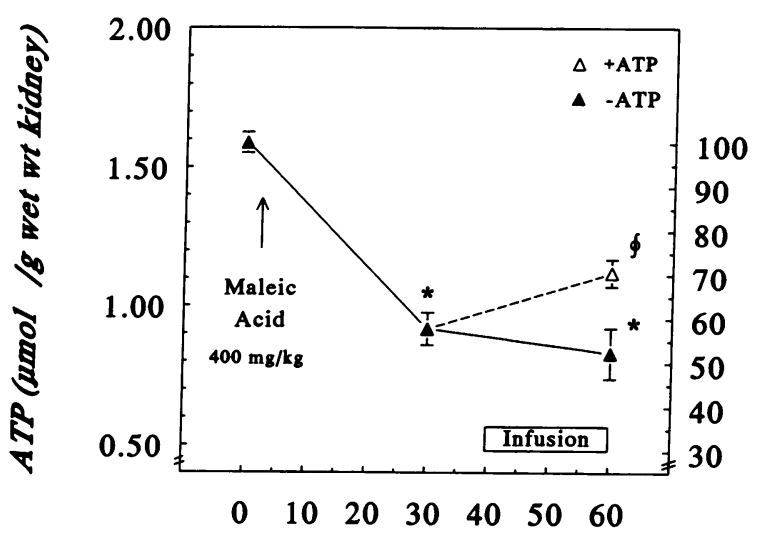

TIME (min)

Figure 6. Effect of exogenous ATP- $\mathrm{MgCl}_{2}$ on tissue ATP following high dose maleic acid. Solid triangles, control animals $(n=17)$ and animals $30 \min (n=5)$ and $60 \min (n=6)$ after treatment with 400 $\mathrm{mg} / \mathrm{kg}$ of maleic acid without exogenous ATP- $\mathrm{MgCl}_{2}$; open triangle, animals treated with $400 \mathrm{mg} / \mathrm{kg}$ of maleic acid followed by $25 \mu \mathrm{mol}$ of exogenous ATP- $\mathrm{MgCl}_{2}(n=6)$. Renal ATP significantly decreased to $57.9 \%$ of control values by $30 \mathrm{~min}$ and $52.2 \%$ of control values by 60 min following maleic acid $\left({ }^{*} P<0.05\right)$. Administration of exogenous ATP- $\mathrm{MgCl}_{2}$ significantly increased tissue ATP to $70.4 \%$ of control values $60 \mathrm{~min}$ following maleic acid $(\S P<0.05$ vs. both 30 and 60 min after maleic acid without exogenous ATP- $\mathrm{MgCl}_{2}$ ).

and epithelial cells (27). We have recently demonstrated that the majority of proximal tubule apical F-actin disruption occurs during the first 5 min of in vivo ischemia (10), concurrent with rapidly declining ATP levels. Experimental ischemic injury in vivo also results in partial loss of proximal tubule polarity, with resultant decreases in tubular reabsorption of sodium (2). A recent study showed that chemically induced ATP depletion in LLC-PK ${ }_{1}$ cells resulted in decreases in G-actin indicative of actin polymerization, along with dissociation of $\mathrm{Na}^{+}$$\mathrm{K}^{+}$-ATPase both from the cytoskeleton and the basolateral membrane, consistent with loss of polarity (28). Using an isolated perfused kidney system, we have previously demonstrated that cytochalasin D, a selective disrupter of microfilaments, causes significant proximal tubular dysfunction (29). Thus, the actin cytoskeleton plays a role in the maintenance of epithelial cell structure and polarity required for normal cell function.

Maleic acid has been used as an experimental model of proximal renal tubular acidosis because it causes decreased reabsorption of sodium, bicarbonate, chloride, protein, glucose, and phosphorus (30-36). Because it is transported by the same organic transporter that also transports para-aminohippuric acid, maleic acid is selectively taken up and concentrated in the proximal tubule cells of the kidney. Due to specific inhibition of the Krebs cycle in the mitochondria of proximal tubule cells, maleic acid causes decreases in $\operatorname{ATP}(37,38)$. Although maleate is the trans-isomer of fumarate, rather than interfering with fumarase, it most likely forms maleyl coA, which acts to deplete the Krebs cycle of coenzyme A $(39,40)$. Although early studies demonstrated inhibition of membrane $\mathrm{Na}^{+}$, $\mathrm{K}^{+}$-ATPase in vivo (37), more recent in vitro vesicle studies have demonstrated that maleic acid does not directly alter membrane transporters $(41,42)$. Thus, it has been proposed that decreases in cellular ATP induced by maleic acid starve the ionic pumps of energy, resulting in loss of unidirectional transport of solute.

A review of previous studies demonstrates that maleic acid does not act as an appropriate model of proximal renal tubular acidosis. In contrast to clinical renal tubular acidosis, maleic acid results in significant apical membrane disruption and vacuolization at both light and electron microscopic levels $(35,38$, 43-45). Additionally, in the few instances where GFR has been measured, prior studies have shown significant decreases in GFR with maleic acid $(30,31,33-35)$, another feature inconsistent with proximal renal tubular acidosis. The decrease in GFR has been postulated to be due either to increased production of adenosine (46) or to backleak of inulin (47). Before this study, a systematic dose response has never been performed for tissue ATP, renal function, and most significantly, F-actin location and net cellular actin polymerization.

We postulate that maleic acid acts as a model of selective cortical ATP depletion in vivo, thus mimicking ischemic injury. Although there are no other viable in vivo models of selective renal ATP depletion, Shanley and colleagues demonstrated that infusion of multiple metabolic inhibitors into an isolated perfused kidney system resulted in proximal tubule apical membrane structural alterations and "clubbing" characteristic of experimental ischemia and hypoxic injury (48). Using maleic acid, we have demonstrated a significant dose response for renal ATP depletion, with concurrent dose-dependent alterations in proximal tubule apical F-actin, GFR, and tubular sodium reabsorption similar to that seen during ischemic injury. Raising tissue ATP with exogenous ATP in this in vivo maleic acid model resulted in significant reversal of this process, both structurally and functionally. Using time-course experiments, we demonstrated that exogenous ATP did not just prevent maleic acid-induced apical losses of F-actin, but actually resulted in relocation of F-actin from the cytoplasm back to the apical surface of proximal tubule cells. This is the first demonstration that microfilament structure and cellular location in vivo can be modified by exogenous ATP. Concurrent with this reversal of microfilament structure and cellular location by exogenous ATP, both GFR and tubular reabsorption of sodium significantly improved. These interventional data strongly support the hypothesis that microfilament structure and cellular location necessary for normal function of proximal tubules in vivo are dependent on cellular ATP levels. Similar to experimental ischemic injury in vivo (10), distal tubules did not alter their F-actin structure with renal ATP depletion or repletion in this model.

Very little is known regarding the dynamics of actin polymerization in vivo. In vitro, $\mathrm{G}$-actin polymerizes to $\mathrm{F}$-actin via irreversible hydrolysis of ATP (49). Only very small amounts of G-actin are required for filament growth in vitro, so the overwhelming majority of actin is present in the polymerized form. In contrast, approximately half of actin in cells exists in the monomeric form (50), and microinjection of G-actin into normal rat kidney cells does not result in further growth of existing microfilaments (51). The maintenance of this depolymerized state is most likely due to inhibition of polymerization by actin-associated proteins ( 51 ). Additionally, $\mathrm{LLC}^{-\mathrm{PK}_{1} \text { cells }}$ treated with metabolic inhibitors have demonstrated decreased amounts of cellular G-actin, indicating net polymerization 


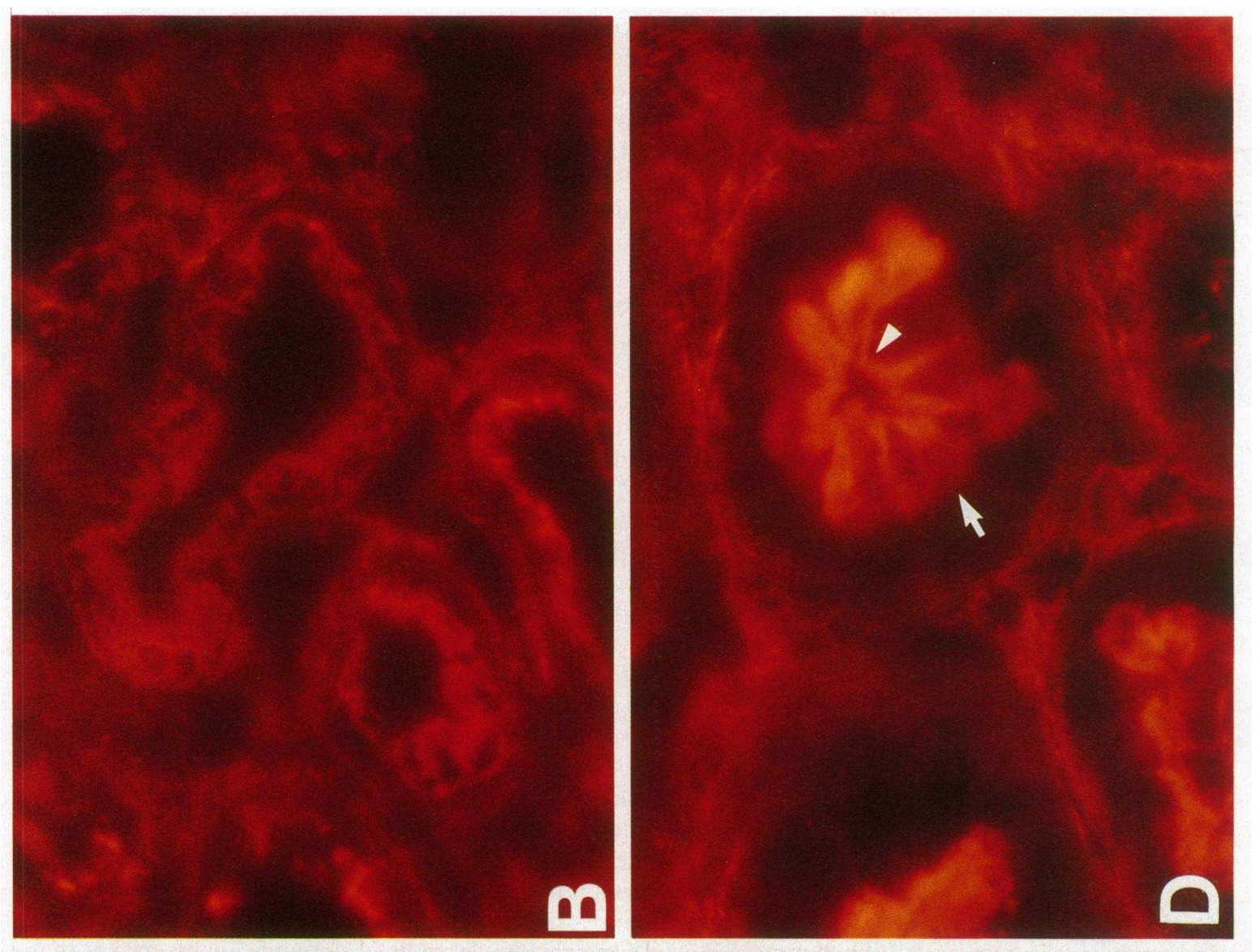

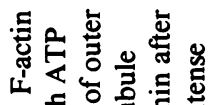

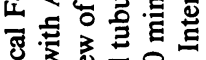

을

要

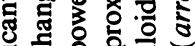

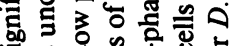

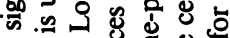

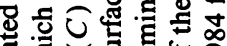

궁

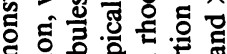

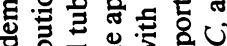

을 西

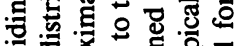

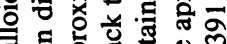

ส] $\equiv$

원

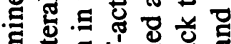

돈

ठ

0 山范票

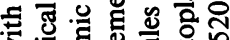

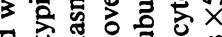

政

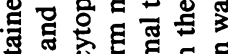

क.

S

论

हैं

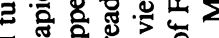

ส 융

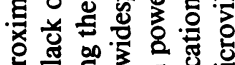

원

حิ

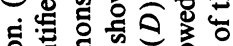

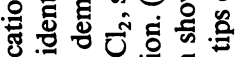

8 格

उ。

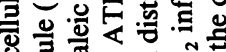

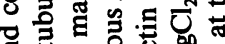

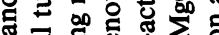

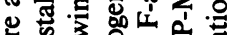

类言

흥 응 졍

룽ㅇㅇ

के क्ष

-

$\varnothing$

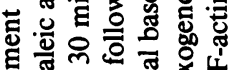

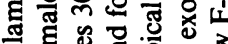

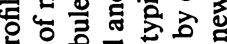

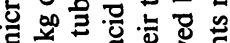

일

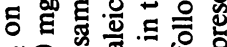

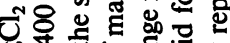

更

1

는

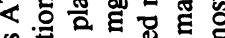

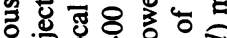

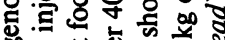

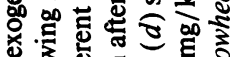

डै

응혀열

응

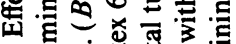

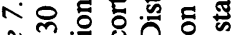

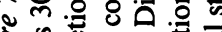

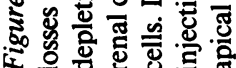

?

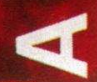


with decreased cellular energy levels (28). Based on these data, investigators have postulated that cellular energy is required to maintain a depolymerized rather than a polymerized state of actin (50).

Our data suggest that energy may be required for both polymerization and depolymerization of different actin pools in vivo, allowing for rapid interconversion between monomeric and filamentous forms of actin. As ATP levels decreased in proximal tubule cells, cytoplasmic F-actin appeared while apical F-actin was either lost into the lumen or depolymerized. Restoration of cellular ATP levels structurally resulted in relocation of F-actin from the cytoplasm back to the apical surface. If this change in F-actin location was due to movement of microfilaments rather than alterations in polymerization, then we would expect no change in net cellular actin polymerization with ATP depletion and repletion. Net cellular actin polymerization, which represents the sum of actin pools, increased with maleic acid-induced ATP depletion in vivo, similar to that seen during ATP depletion in the LLC-PK 1 proximal tubule cell model (28). Alterations in the cytoskeleton in vivo occurred with smaller decrements in measured ATP than that
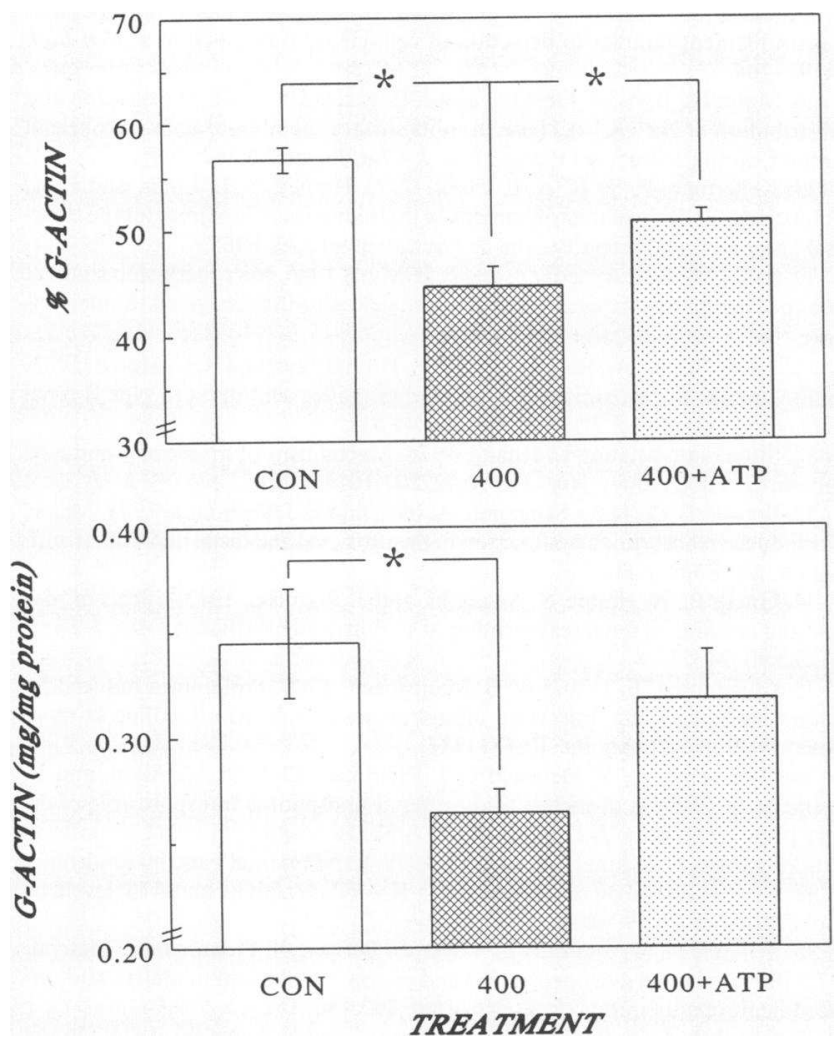

Figure 8. Effect of exogenous ATP following maleic acid on cellular actin polymerization. Actin was quantified with the DNAase inhibition assay $60 \mathrm{~min}$ following $400 \mathrm{mg} / \mathrm{kg}$ of maleic acid without and with exogenous ATP- $\mathrm{MgCl}_{2}$. Total actin remained unchanged in all treatment groups (data not shown). Following maleic acid alone, G-actin significantly decreased from $56.7 \pm 1.2 \%$ to $44.7 \pm 1.8 \%$ (top) and from $0.345 \pm 0.026$ to $0.264 \pm 0.011 \mathrm{mg} / \mathrm{mg}$ protein (bottom). Relative to maleic acid alone, maleic acid plus exogenous ATP significantly increased the percent of G-actin to $50.8 \pm 1.1$, and increased G-actin quantity to $0.318 \pm 0.023 \mathrm{mg} / \mathrm{mg}$ protein, nearing but not reaching significance. $n=6$ in each group, ${ }^{*} P<0.05$.

\section{A}

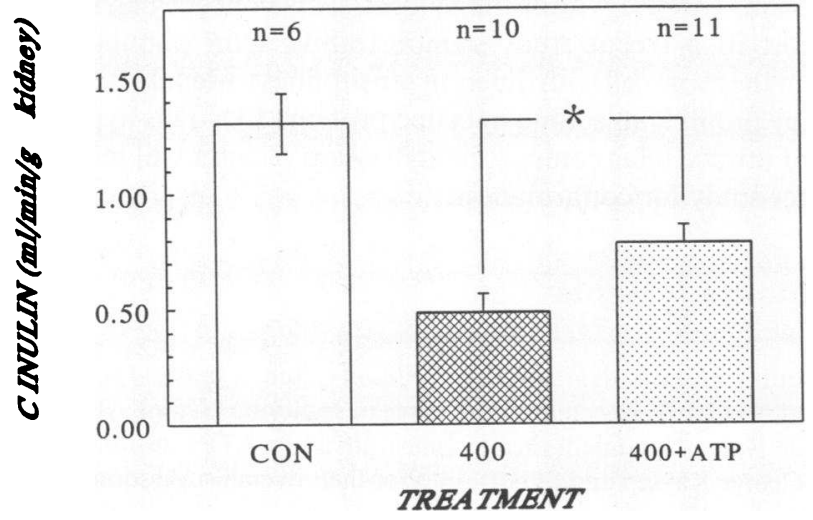

B

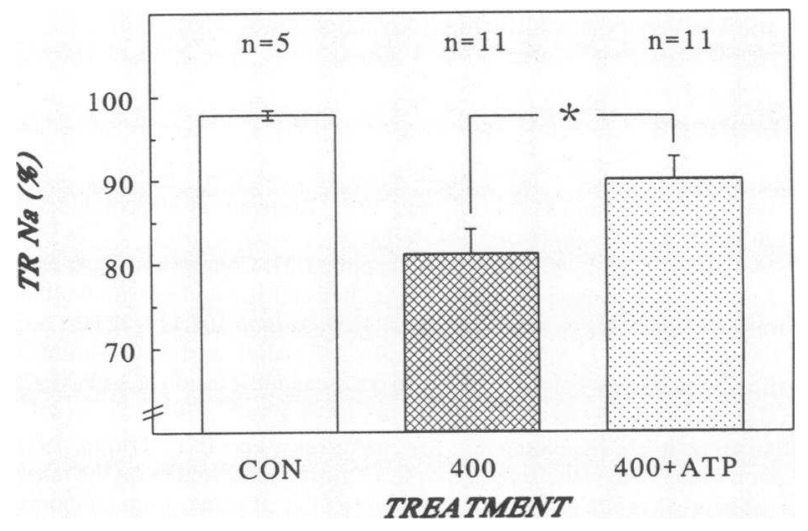

Figure 9. Effect of exogenous ATP- $\mathrm{MgCl}_{2}$ on glomerular filtration rate (GFR) and tubular reabsorption of sodium $\left(\mathrm{TR}_{\mathrm{Na}}\right)$ following maleic acid. $60 \mathrm{~min}$ after $400 \mathrm{mg} / \mathrm{kg}$ of maleic acid, both GFR and $T R_{\mathrm{Na}_{\mathrm{a}}}$ decreased relative to equimolar $\mathrm{NaCl}$ controls. $(A)$ Following infusion with $25 \mu \mathrm{mol}$ of ATP- $\mathrm{MgCl}_{2}$, GFR significantly increased to $0.79 \pm 0.08 \mathrm{ml} / \mathrm{min}$ per $\mathrm{g}$ from $0.49 \pm 0.08 \mathrm{ml} / \mathrm{min}$ per $\mathrm{g}$ with 400 $\mathrm{mg} / \mathrm{kg}$ of maleic acid alone. $(B)$ Following exogenous ATP infusion, $\mathrm{TR}_{\mathrm{Na}}$ significantly increased to $90.1 \pm 2.7 \%$ from $81.2 \pm 3 \%$ with 400 $\mathrm{mg} / \mathrm{kg}$ of maleic acid alone. ${ }^{*} P<0.05$.

seen in cell culture (28), perhaps due to contribution from other unaffected cortical cells. With ATP repletion, net actin polymerization decreased back toward control values, yet new F-actin formed at the apical surface. The differential polymerization of apical and cytoplasmic F-actin with ATP depletion and repletion suggests that there may be two pools of actin in epithelial cells that respond in contrasting fashions to the same cellular ATP levels. This hypothesis is further supported by our recent studies of $F$-actin structure and cellular location during reperfusion following ischemia (Kellerman, P. S., manuscript in preparation; see also reference 52). When renal ATP recovered to levels similar to that seen with higher dose maleic acid, apical F-actin losses continued while cytoplasmic polymerization of F-actin identical to that seen with maleic acid was observed. Thus, there may be threshold cellular ATP levels necessary for polymerization of different actin pools. The differential response to adenine nucleotides by the apical and 
cytoplasmic pools of actin may be maintained via differences in their actin-associated proteins, since there are unlikely to be structural barriers within the cytosol. This concept has some support in a recent study demonstrating actin populations within the same cell with different sensitivities to depolymerization by profilin, an actin-associated protein (53). This hypothesis of intracellular compartmentalization of actin will require further study for confirmation.

\section{Acknowledgments}

The author extends his grateful appreciation to Judy Lund and Katherine Sanders for their technical assistance in sectioning, Gunilla Thulin and Dr. Karen Gaudio for their technical advice on ATP infusions, and Drs. George Kaysen and Stuart Linas for their overall suggestions and guidance.

This work was supported by a Grant-In-Aid from the American Heart Association, California affiliate, a Young Investigator Award from the National Kidney Foundation, and general research funds from the University of California, Davis School of Medicine.

\section{References}

1. Warnick, C. T., and H. M. Lazarus. 1981. Recovery of nucleotide levels after cell injury. Can. J. Biochem. 59:116-121.

2. Molitoris, B. A., L. K. Chan, J. I. Shapiro, J. D. Conger, and S. A. Falk. 1989. Loss of epithelial polarity: a novel hypothesis for reduced proximal tubule $\mathrm{Na}+$ transport following ischemic injury. J. Membr. Biol. 107:119-127.

3. Siegel, N. J., M. J. Avison, H. F. Reilly, J. R. Alger, and R. G. Shulman. 1983. Enhanced recovery of renal ATP with postischemic infusion of ATP- $\mathrm{MgCl}_{2}$ determined by ${ }^{31}$ P-NMR. Am. J. Physiol. 245:F530-F534.

4. Glaumann, B., H. Glaumann, I. K. Berezesky, and B. F. Trump. 1977. Studies on cellular recovery from injury. II. Ultrastructural studies on the recovery of the pars convoluta of the proximal tubule of the rat kidney from temporary ischemia. Virchows Arch. B. Cell Pathol. 24:1-18.

5. Glaumann, B., H. Glaumann, and B. F. Trump. 1977. Studies of cellular recovery from injury. III. Ultrastructural studies on the recovery of the pars recta of the proximal tubule ( $\mathrm{p} 3$ segment) of the rat kidney from temporary ischemia. Virchows Arch. B. Cell Pathol. 25:281-308.

6. Donohoe, J. F., M. A. Venketachalam, D. B. Bernard, and N. G. Levinsky. 1978. Tubular leakage and obstruction after renal ischemia: structural-functional correlations. Kidney Int. 13:208-222.

7. Venketachalam, M. A., D. B. Jones, H. G. Rennke, D. Sandstrom, and Y. Patel. 1981. Mechanism of proximal tubule brush border loss and regeneration following mild renal ischemia. Lab. Invest. 45:355-365.

8. Johnston, P. A., H. G. Rennke, and N. G. Levinsky. 1984. Recovery of proximal tubular function from ischemia. Am. J. Physiol. 246:F159-F166.

9. Molitoris, B. A., and R. Kinne. 1987. Ischemia induces surface membrane dysfunction. Mechanism of altered $\mathrm{Na}+$-dependent glucose transport. J. Clin. Invest. 80:647-654.

10. Kellerman, P. S., and R. T. Bogusky. 1992. Microfilament disruption occurs very early in ischemic proximal tubule cell injury. Kidney Int. 42:896-902.

11. Fletcher, W. H., and C. V. Byus. 1982. Direct cytochemical localization of catalytic subunits dissociated from cAMP-dependent protein kinase in Reuber H-35 hepatoma cells. I. Development and validation of fluorescinated inhibitor. J. Cell Biol. 93:719-726.

12. Fletcher, W. H., S. M. Van Patten, H. C. Cheng, and D. A. Walsh. 1986. Cytochemical identification of the regulatory subunit of the cAMP-dependent protein kinase by use of fluorescently labeled catalytic subunit. J. Biol. Chem. 261:5504-5513.

13. Murray, S. A., and W. H. Fletcher. 1984. Hormone-induced intercellular signal transfer dissociates cyclic AMP-dependent protein kinase. J. Cell Biol. 98:1710-1719.

14. Huang, Z., R. P. Haugland, W. You, and R. P. Haugland. 1992. Phallotoxin and actin binding assay by fluorescence enhancement. Anal. Biochem. 200:199-204.

15. Blikstad, I., F. Markey, L. Carlsson, T. Persson, and U. Lindberg. 1978. Selective assay of monomeric and filamentous actin in cell extracts, using inhibition of deoxyribonuclease I. Cell 15:935-943.

16. Cheung, H. T., C. A. Rehwaldt, J. S. Twu, N. S. Liao, and A. Richardson. 1987. Aging and lymphocyte cytoskeleton: age-related decline in the state of actin polymerization in T lymphocytes from Fischer F344 rats. J. Immunol. 138: 32-36.

17. Lowry, O. H., N. J. Rosebrought, A. L. Farr, and R. J. Randall. 1951. Protein measurement with the Folin phenol reagent. J. Biol. Chem. 193: 265-275.

18. Williamson, J. R., and B. E. Corkey. 1969. Adenosine 5'-triphosphatedetermination with hexokinase and glucose-6-phosphate dehydrogenase. Methods Enzymol. 13:488-491.

19. Lampecht, W., and I. Trautschold. 1974. Nucleotides, coenzymes, and related compounds: HK and G6P-DH. In Methods of Enzymatic Analysis. H. U. Bergmeyer, editor. Academic Press, Inc., New York. 2101-2110.

20. Molitoris, B. A., P. D. Wilson, R. W. Schrier, and F. R. Simon. 1985 Ischemia induces partial loss of surface membrane polarity and accumulation of putative calcium ionophores. J. Clin. Invest. 76:2097-2105.

21. Pollard, T. D. 1986. Assembly and dynamics of the actin filament system in nonmuscle cells. J. Cell Biochem. 31:87-95.

22. Korn, E. D., M. Carlier, and D. Pantaloni. 1987. Actin polymerization and ATP hydrolysis. Science (Wash. DC). 238:638-644.

23. Mooseker, M. D. 1985 . Organization, chemistry, and assembly of the cytoskeletal apparatus of the intestinal brush border. Annu. Rev. Cell Biol. 1:269293.

24. Coudrier, E., D. Kerjaschki, and D. Louvard. 1988. Cytoskeletal organization and submembranous interactions in intestinal and renal brush borders. Kidney Int. 34:309-320.

25. Bershadsky, A. D., V. I. Gelfand, T. M. Svitkina, and I. S. Tint. 1980 Destruction of microfilament bundles in mouse embryo fibroblasts treated with inhibitors of energy metabolism. Exp. Cell Res. 127:421-429.

26. Bereiter-Hahn, J., U. Tillmann, and M. Voth. 1984. Interaction of metabolic inhibitors with actin fibrils. Cell Tissue Res. 238:129-134.

27. Sanger, J. W., and J. M. Sanger. 1983. Differential response of three types of actin filament bundles to depletion of cellular ATP levels. Eur. J. Cell Biol. 31:197-204.

28. Molitoris, B. A., A. Geerdes, and J. R. McIntosh. 1991. Dissociation and redistribution of $\mathrm{Na}^{+}, \mathrm{K}^{+}$-ATPase from its surface membrane actin cytoskeletal complex during cellular ATP depletion. J. Clin. Invest. 88:462-469.

29. Kellerman, P. S., R. A. F. Clark, C. A. Hoilien, S. L. Linas, and B. A. Molitoris. 1990. Role of microfilaments in maintenance of proximal tubule structural and functional integrity. Am. J. Physiol. 259:F27.9-F285.

30. Bank, N., H. S. Aynedjian, and B. F. Mutz. 1986. Microperfusion study of proximal tubule bicarbonate transport in maleic acid-induced renal tubular acidosis. Am. J. Physiol. 250:F476-F482.

31. Al-Bander, H. A., R. A. Weiss, M. H. Humphreys, and R. C. Morris. 1983. Dysfunction of the proximal tubule underlies maleic acid-induced type II renal tubular acidosis. Am. J. Physiol. 243:F604-F611.

32. Silverman, M., and L. Huang. 1976. Mechanism of maleic acid-induced glucosuria in dog kidney. Am. J. Physiol. 231:1024-1032.

33. Brewer, E. D., H. O. Senekjian, A. Ince, and E. J. Weinman. 1983. Maleic acid-induced reabsorptive dysfunction in the proximal and distal nephron. Am.J. Physiol. 245:F339-F344.

34. Gmaj, P., A. Hoppe, S. Angielski, and J. Rogulski. 1973. Effects of maleate and arsenite on renal reabsorption of sodium and bicarbonate. Am. J. Physiol. 225:90-94.

35. Christensen, E. I., and A. B. Maunsbach. 1980. Proteinuria induced by sodium maleate in rats: Effects on ultrastructure and protein handling in renal proximal tubule. Kidney Int. 17:771-787.

36. Guntupalli, J., V. Delaney, E. J. Weinman, D. Lyle, M. Allon, and E. Bourke. 1991. Effects of maleic acid on renal phosphorus transport: role of dietary phosphorus. Am. J. Physiol. 30:F227-F237.

37. Kramer, H. J., and H. C. Gonick. 1979. Experimental Fanconi syndrome. I. Effect of maleic acid on renal cortical Na-K-ATPase activity and ATP levels. $J$. Lab. Clin. Med. 76:799-808.

38. Scharer, K., T. Yoshida, L. Voyer, S. Berlow, G. Pietra, and J. Metcoff. 1972. Impaired renal gluconeogenesis and energy metabolism in maleic acid-induced nephropathy in rats. Res. Exp. Med. 157:136-152.

39. Rogulski, J., A. Pacanis, W. Adamowicz, and S. Angielski. 1974. On the mechanism of maleate action on rat kidney mitochondria. Effect on oxidative metabolism. Acta Biochim. Pol. 21:403-413.

40. Szczepanska, M., and S. Angielski. 1980. Prevention of maleate-induced tubular dysfunction by acetoacetate. Am. J. Physiol. 239:F50-F56.

41. Le Grimellec, C., S. Carriere, J. Cardinal, and M. C. Giocondi. 1982. Effect of maleate on membrane physical state of brush border and basolateral membranes of the dog kidney. Life Sci. 30:1107-1111.

42. Reynolds, R., P. D. McNamara, and S. Segal. 1978. On the maleic acid induced Fanconi syndrome: Effects on transport by isolated rat kidney brushborder membrane vesicles. Life Sci. 22:39-44.

43. Verani, R. R., E. D. Brewer, A. Ince, J. Gibson, and R. E. Bulger. 1982. Proximal tubular necrosis associated with maleic acid administration to the rat. Lab. Invest. 46:79-88.

44. Rosen, V. J., H. J. Kramer, and H. C. Gonick. 1973. Experimental Fan- 
coni syndrome. II. Effect of maleic acid on renal tubular ultrastructure. Lab. Invest. 28:446-455.

45. Pfaller, W., M. Joannidis, G. Gstraunthaler, and P. Kotanko. 1989. Quantitative morphologic changes of nephron structures and urinary enzyme activity pattern in sodium-maleate-induced renal injury. Renal Physiol. Biochem. 12:56-64.

46. Arend, L. J., C. I. Thompson, M. A. Brandt, and W. S. Spielman. 1986 Elevation of intrarenal adenosine by maleic acid decreases GFR and renin release. Kidney Int. 30:656-661.

47. Maeseka, J. K., and M. McCaffery. 1980. Evidence for renal tubular leakage in maleic acid-induced Fanconi syndrome. Am. J. Physiol. 239:F507F513.

48. Shanley, P. F., M. Brezis, K. Spokes, P. Silva, F. H. Epstein, and S. Rosen. 1986. Differential responsiveness of proximal tubule segments to metabolic inhibitors in the isolated perfused rat kidney. Am. J. Kidney Dis. 7:76-83.
49. Carlier, M. F., D. Pantaloni, J. A. Evans, P. K. Lambooy, E. D. Korn, and M. R. Webb. 1988. The hydrolysis of ATP that accompanies actin polymerization is essentially irreversible. FEBS (Fed. Eur. Biochem. Soc.) Lett. 235:211214.

50. Stossel, T. P. 1989. From signal to pseudopod. How cells control cytoplasmic actin assembly. J. Biol. Chem. 264:18261-18264.

51. Sanders, M. C., and Y. L. Wang. 1990. Exogenous nucleation sites fail to induce detectable polymerization of actin in living cells. J. Cell Biol. 110:359365 .

52. Kellerman, P. S., and S. L. Norenberg. 1991. Proximal tubule F-actin polymerizes and moves apically in a time-dependent manner during reperfusion following ischemia. J. Am. Soc. Nephrol. 2:469. (Abstr.)

53. Cao, L. G., G. G. Babcock, P. A. Rubenstein, and Y. L. Wang. 1992. Effects of profilin and profilactin on actin structure and function in living cells. $J$. Cell Biol. 117:1023-1029. 